\title{
USO DE METODOLOGIAS PARTICIPATIVAS NA REALIZAÇÃO DOS DIREITOS HUMANOS À ÁGUA E AO SANEAMENTO EM UMA COMUNIDADE RURAL (QUILOMBOLA) EM MINAS GERAIS
}

\section{USE OF PARTICIPATORY METHODOLOGIES IN THE REALIZATION OF HUMAN RIGHTS TO WATER AND SANITATION IN A RURAL (QUILOMBOLA) COMMUNITY IN MINAS GERAIS STATE, BRAZIL}

\author{
Rafael Kopschitz Xavier Bastos ${ }^{(1)}$ \\ Civil, Universidade Federal de Viçosa. \\ Gabriela Vieria Capobiango ${ }^{(2)}$ \\ Universidade Federal de Viçosa. \\ Flávia Barros Vitorino ${ }^{(3)}$ \\ Graduanda em Engenharia Ambiental pela Universidade Federal de Viçosa \\ Thiago José Dias Godinho ${ }^{(4)}$ \\ Graduando em Engenharia Ambiental pela Universidade Federal de Viçosa \\ Matheus de Brito Correa ${ }^{(5)}$ \\ Graduado em Engenharia Ambiental pela Universidade Federal de Viçosa \\ E-mail(1): rkxb@ufv.br
}

Engenheiro Civil, Universidade Federal de Juiz de Fora; especialização em Engenharia de Saúde Pública, ENSP/Fiocruz; doutorado em Engenharia de Saúde Pública, University of Leeds/UK; Professor Titular, Departamento de Engenharia

Graduada em Engenheira Ambiental, com mestrado em Engenharia Civil, área de concentração sanitária e ambiental pela

\section{RESUMO}

Relata-se neste artigo o processo de mobilização social e participação comunitária com vistas à implantação de melhorias de esgotamento sanitário e abastecimento de água em uma comunidade quilombola no estado de Minas Gerais. Descrevem-se os recursos metodológico-participativos utilizados em um projeto de extensão e discute-se o envolvimento dos(as) participantes na construção compartilhada de conhecimentos, na implantação de melhorias sustentáveis de saneamento e, por fim, a elevação da consciência sobre o saneamento enquanto direito humano.

\begin{abstract}
This article reports on the process of social mobilization and community participation with a view to implementing water supply and sanitation improvements in a quilombola community in the state of Minas Gerais, Brazil. The methodologicalparticipatory resources used in an extension project are described and the involvement of the participants in the shared construction of knowledge, in the implementation of sustainable sanitation improvements and, finally, in raising awareness about sanitation as a human right, is discussed.
\end{abstract}

Palavras-chave: comunidades tradicionais, saneamento rural, diagnóstico rápido participativo

Key words: traditional communities, rural sanitation, rapid rural appraisal

\section{INTRODUÇÃO}

Historicamente, a extensão rural no Brasil foi marcada pela ideia de transferência de tecnologia, por meio de relações rígidas e verticais entre técnicos extensionistas e agricultores, sem considerar as condições socioculturais e ambientais do território, tão pouco os saberes populares locais (OLIVEIRA, 2015). O modelo de intervenção em saneamento no Brasil tem sido também fundamentalmente tecnicista e muito frequentemente não considera o contexto local, o que impacta negativamente a efetividade de soluções impostas, sobretudo no ambiente rural devido à proximidade das tecnologias aos indivíduos (SOUZA et al., 2015). Em contraposição a este modelo, e de forma mais ampla na esteira do processo de redemocratização do país, a partir de década de 1980 a participação popular passou a ser considerada na formulação de políticas públicas, na elaboração de projetos e em intervenções comunitárias; ganha então impulso a formulação de uma grande variedade de "metodologias participativas" de diagnóstico e planejamento (SOUZA, 2009). Nesse contexto, e 
de início com aplicação mais voltada ao meio rural, surge um conjunto de métodos denominado primeiramente Diagnóstico Rápido Participativo e que, após algumas adaptações e aperfeiçoamentos com origem nos trabalhos de Robert Chambers nos Estados Unidos, passou a ser conhecido como Diagnóstico Rural Participativo - DRuP (PEREIRA, 1998). No Brasil, o DRuP tem se efetivado como a metodologia de escolha por entidades e organizações em processos de diagnóstico e planejamento rural, particularmente nos assentamentos rurais (SOUZA, 2009).

Mais recentemente, participação e sustentabilidade passaram a compor os princípios da declaração dos direitos humanos à água e ao saneamento (DHAS) pelas Nações Unidas, juntamente com critérios de não discriminação e igualdade, prestação de contas / responsabilização e acesso à informação; princípios estes que se conectam ao conteúdo normativo dos DHAS: disponibilidade, qualidade e acessibilidade (ALBUQUERQUE, 2014). Assim, na perspectiva dos DHAS, intervenções em saneamento no meio rural devem se pautar em processos e recursos metodológicos que privilegiem a participação informada da população, como requisito para aceitabilidade e sustentabilidade.

Neste sentido, apresentam-se aqui os processos participativos e os procedimentos metodológicos utilizados em um projeto de extensão em saneamento rural desenvolvido na comunidade quilombola Córrego do Meio, situada na zona rural de Airões, distrito de Paula Cândido, Zona da Mata - MG. O projeto vem se mantendo desde 2015, ainda que não de forma contínua. Em uma primeira fase (concluída em 2018) foram implantadas melhorias de esgotamento sanitário; o projeto foi retomado em 2021, agora dedicado a melhorias de abastecimento de água (nesse interim, foram realizadas ações pontuais de acompanhamento da operação e manutenção dos sistemas de esgotos). Ambas as fases foram marcadas por abordagens e métodos de maneira a fomentar a construção de saberes na identificação de problemas e soluções de saneamento (esgotamento sanitário e abastecimento de água), bem como a tomada de decisões pela própria comunidade sobre o que implantar, onde e para quem (SANTOS, 2018; CAPOBIANGO, 2019).

\section{METODOLOGIA / DESENVOLVIMENTO DO TRABALHO}

O projeto tem por fundamentação teórica-metodológica os ensinamentos de Paulo Freire (FREIRE,; 1996) e a "metodologia transversal" (CATALÃO, 2006), em que se busca conexão entre o saber técnico-científico e o saber fazer, levando em conta o saber prévio do(a) treinando(a) que, neste processo, é requalificado, apropriado como um novo saber. Os métodos empregados no desenvolvimento do projeto podem, em sua maioria, ser enquadrados no rol das técnicas de Diagnóstico Rápido Participativo (DRP). ou suas variantes conhecidas como Diagnóstico Rural Participativo (DRuP) (VERDEJO, 2006) e Diagnóstico Rápido Participativo Emancipador (DRPE), (PEREIRA, 1998). DRuP pode ser definido como "uma família de abordagens e métodos que propiciam a população local compartilhar, analisar e aprimorar seus conhecimentos a respeito de suas próprias condições de vida, com objetivo de planejar e agir (CHAMBERS, 1994). O acréscimo do termo "emancipador" traz a perspectiva "Freiriana" de "processo de conscientização das pessoas que lhes permita superar uma situação de dependência e tutorial" (PEREIRA, 1998). Nesta ótica, foram desenvolvidas diversas atividades participativas e utilizados recursos didático-pedagógicos, com intuitos de, por etapas e nesta ordem, promover / proporcionar: (i) reflexões sobre saneamento e suas relações com a saúde e o meio ambiente (ii) o reconhecimento / problematização da situação de saneamento da comunidade, (iii) a apropriação por parte da comunidade de conhecimentos técnicos sobre sistemas descentralizados de abastecimento de água e de esgotamento sanitário; (iv) a escolha de soluções adequadas à realidade local; e (v) seleção das famílias a serem beneficiadas (CAPOBIANGO, 2019). No item a seguir são apresentadas as técnicas utilizadas, localizando sua aplicação nas duas fases do projeto (Fase 1 -esgotos e Fase 2-água) e respectivas etapas - os itens (i) a (v) citados no parágrafo anterior. Essa descrição é acompanhada de discussão sobre o alcance e os resultados esperados de "metodologias participativas". Descrições complementares / exemplos de 
aplicação dessas ferramentas metodológicas podem ser encontradas em Verdejo (2006), Sousa (2009); Oliveira (2015).

\section{RESULTADOS ALCANÇADOS}

\subsection{Fase 1 - esgotamento sanitário}

Problematização sobre a relação saneamento e saúde e a situação local de saneamento: caminhada transversal, mapeamento participativo e oficinas interativas sobre o ciclo da água

Essas atividades foram realizadas no início do projeto com vistas à melhor compreensão da realidade e dos problemas locais de saneamento e a dar início ao processo de mobilização e sensibilização em relação à temática do saneamento. A caminhada transversal se faz em um percurso realizado junto a informantes locais; estimulam-se olhares atentos ao ambiente ao redor e direcionados à construção de um diagnóstico da situação local de saneamento e relações com o ambiente e a saúde Complementarmente, com o mapeamento participativo se buscou a construção de um mapa a partir de percepções e conhecimentos que os(as) moradores(as) já possuíam sobre o ambiente onde vivem e, ou que tenham sido captados ou aguçados durante a caminhada (Figura 1). Como saldo positivo dessa etapa merecem destaque: (i) a identificação de áreas com maior exposição a fatores de risco à saúde, como por exemplo: fontes de água (poços rasos) próximas à locais de criação de animais ou ao leito de córregos receptores de esgotos; (ii) o engajamento de um grupo de mulheres com forte liderança na comunidade, que passou a colaborar no planejamento e execução de todas as atividades do projeto.

Figura 1 - Caminhada transversal e mapeamento participativo.
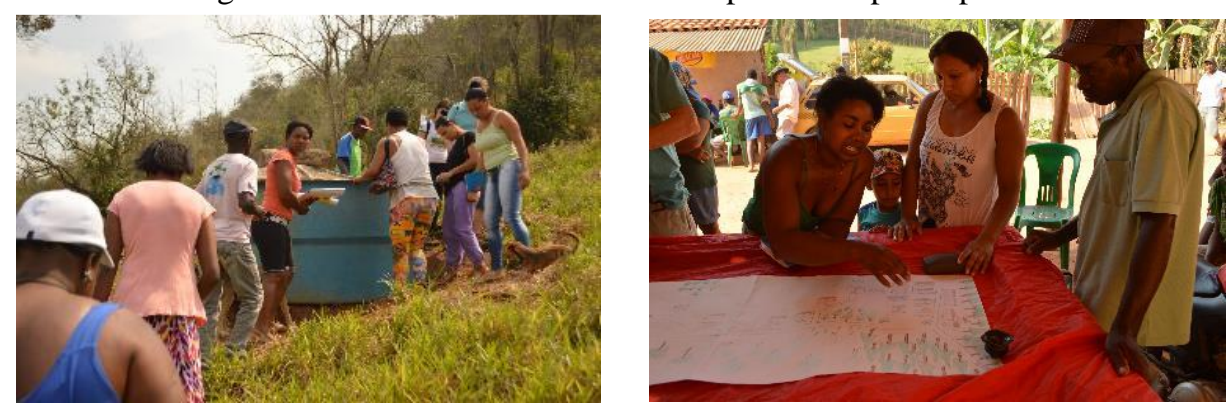

Fonte: Capobiango (2019)

Visando facilitar a compreensão do ciclo da água na natureza e as respectivas especificidades locais, foram realizadas oficinas interativas com os seguintes recursos didáticos, concebidos pela equipe do projeto: (i) cartazes com imagens ilustrando temas como o ciclo da água e a poluição dos corpos hídricos (Figura 2a); (ii) uma caixa de vidro (chamada aqui de "aquário") moldada em seu interior com brita, areia e terra de forma a simular um vale por onde corria um pequeno córrego e o ciclo da água (precipitação, infiltração e escoamento superficial); a introdução de água pela "zona de recarga"(uma garrafa pet de 1,5 L cortada) permitia observar a variação do nível de água no córrego e em um poço (garrafa pet transparente de $500 \mathrm{~mL}$ ); durante a atividade, as pessoas eram instigadas a fazer observações sobre o processo que ali ocorria e possíveis similaridades com a dinâmica local da água e a suscetibilidade de contaminação de poços rasos (Figura 2b); (iii) uma maquete, construída em isopor a partir de uma imagem de satélite, representando o relevo e a rede hidrográfica local com uma fita azul, os moradores identificavam na maquete o curso d'água principal e, com marcadores feitos com alfinetes, localizavam suas casas, fontes de água e de contaminação tais como: fossas ou lançamento de esgotos em cursos d'água; lixeiras, criação de animais (Figura 2c). Ao fim dessas atividades eram estimuladas reflexões relacionando aspectos de uso e ocupação do solo, impactos ambientais e de saúde; era ainda solicitado às pessoas que procurassem vislumbrar possíveis soluções para os problemas de saneamento 
Figura 2. Oficinas participativas sobre ciclo e qualidade da água
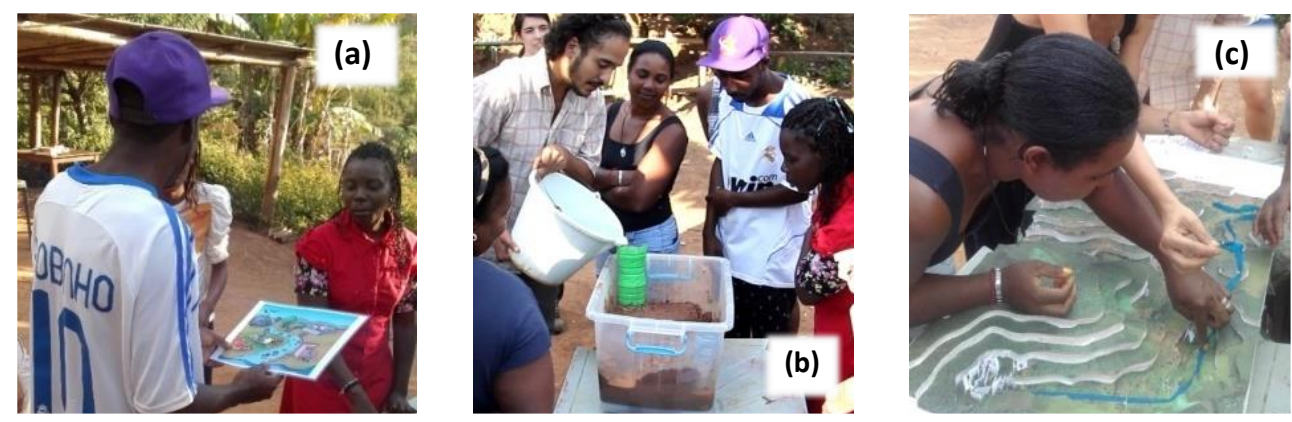

Fonte: Capobiango (2019)

\section{Seleção de tecnologias: material didático-expositivo e Matriz FOFA simplificada}

Primeiro, diferentes sistemas descentralizados de esgotamento sanitário eram apresentados em seus diversos aspectos - princípios de funcionamento, caracterização como unidade de tratamento e, ou de destino final de esgotos, capacidade de tratamento, aspectos construtivos, operação e manutenção, custos; em seguida, após discussão de prós e contras de cada opção, estas eram ordenadas, pelos(as) participantes, por ordem de prioridade. Para apresentação (e discussão) dos sistemas foram preparadas pequenas cartilhas e cartazes com ilustrações e observações sobre suas características. Essa atividade foi desenvolvida de forma expositiva dialogada, com o objetivo de relacionar as características de cada modelo às situações encontradas na comunidade, por exemplo: adequação ao tipo de solo, proximidade de cursos ou fontes de água. Para fomentar a continuidade da discussão, os(as) participantes ficaram com as cartilhas e os cartazes permaneceram expostos (afixados, ou pendurados em um varal) no local das reuniões (Figura 3a) até a oficina seguinte. Havia um receio que o formato expositivo e com veiculação de grande quantidade de informações pudesse inibir a participação da comunidade e comprometer a apropriação de um "saber técnico". Entretanto, isso não se confirmou, pois nas oficinas seguintes as pessoas demonstraram discernimento e desenvoltura na discussão. Em um segundo momento, os(as) participantes se dividiram em grupos correspondentes às sublocalidades da comunidade $e$, de posse de imagens das soluções de esgotos, foi solicitado que cada grupo as ordenasse de acordo com seu entendimento de adequação à sua realidade (Figura $3 \mathrm{~b}$ ).

Em um terceiro momento, foi utilizada uma forma de matriz FOFA - Fortalezas, Oportunidades, Fraquezas e Ameaças, por meio do que se procurar elencar aspectos positivos e desfavoráveis, distinguindo o que é próprio (Fortalezas e Fraquezas) e o que é externo (Oportunidades e Ameaças) (SCHÜTZ; HACON; IGNOTI, 2009). Foram utilizados cartazes com imagens dos sistemas e duas colunas a serem preenchidas com informações referentes a vantagens e desvantagens associadas a cada sistema. Os(as) participantes receberam tarjetas com cores específicas para vantagens e desvantagens, onde deveriam manifestar, por escrito, respectivamente, pontos positivos e negativos de cada sistema e, em seguida, afixar as tarjetas nos cartazes. Nessa atividade, objetivou-se identificar os principais fatores que interferem na tomada de decisão sobre as técnicas de esgotamento sanitário. A seguir, cada participante recebeu pequenos adesivos circulares para que os pregassem, em cada cartaz, nas tarjetas referentes a vantagem e a desvantagem que considerassem mais importantes de cada sistema, possibilitando assim a hierarquização dos fatores. Após esse processo, foi solicitado aos grupos inicialmente formados, que, caso achassem necessário, reordenassem os sistemas, configurando, assim a seleção final dos modelos considerados mais adequados para cada sublocalidade da comunidade.

Figura 3. Oficinas de discussão (a) e de seleção (b,c) de soluções descentralizadas de esgotamento sanitário 


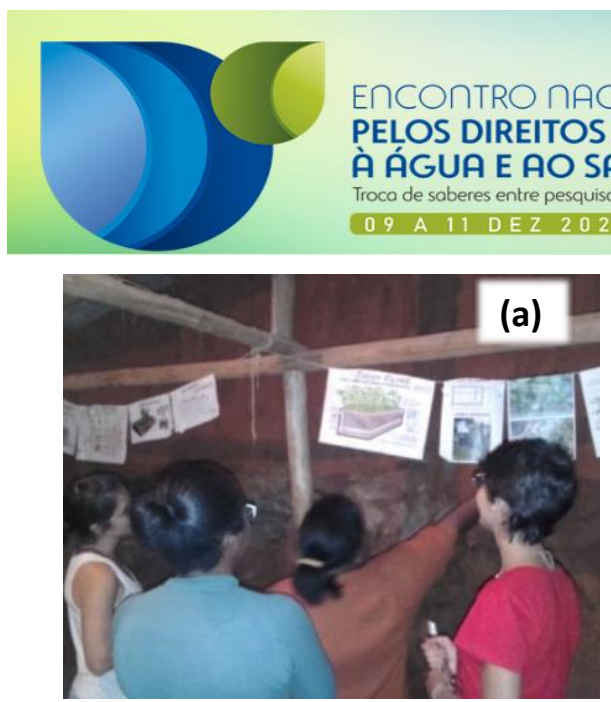

Fonte: Capobiango (2019)

\section{Seleção das residências a serem atendidas}

Como os recursos financeiros do projeto eram limitados, tornou-se necessário selecionar famílias / residências a serem beneficiadas. Para isso, foi preparada uma tabela composta, nas linhas, por uma lista com todas residências da comunidade e, nas colunas, por quatro critérios estabelecidos pelos(as): participação nas oficinas; condições socioeconômicas; situações de risco ambiental e de saúde (por exemplo, casas que lançam esgoto diretamente no córrego e famílias que consumem água não segura), e grupos vulneráveis, incluindo crianças menores de cinco anos e idosos acima de 60 anos. Por fim, os(as) participantes foram orientados a marcar até dez famílias por cada critério, de maneira sigilosa e individual. Foram instalados 18 sistemas, contemplando 22 residências (SANTOS, 2018).

\subsection{Fase 2 - abastecimento de água}

\section{Oficinas sobre segurança da água para consumo humano: material didático-expositivo, material interativo e Árvore de problemas}

Estas atividades tiveram por objetivo reavivar conhecimentos adquiridos na fase anterior sobre as relações água / esgoto e saneamento / saúde, convergindo agora o foco para a promoção do abastecimento seguro de água para uso doméstico. Em um primeiro momento recorreu-se à da Árvore de Problemas - uma ferramenta de análise da relação causa-efeito de vários aspectos de um dado problema; sobre o desenho de um árvore em um cartaz, o problema (no caso, "água ruim") é colocado no tronco; à medida que a discussão avança, tarjetas preenchidas com possíveis causas são afixadas nas raízes; outras, com efeitos, nos galhos e nas folhas (Figura 4a); no debate, se discute quais causas podem ser eliminadas ou controladas (VERDEJO, 2006). A seguir, foram utilizadas duas maquetes em papelão e isopor representando um ambiente peridomiciliar com situações inadequadas de esgotamento sanitário / abastecimento de água (Figura 4b). À cada maquete era associada uma história familiar, que incluía casos de doenças, e cujo cotidiano era contado por meio de animação similar à de teatro de bonecos. Ao final, os(as) participantes eram provocados a refletir sobre as causas das doenças e identificar situações inadequadas de saneamento e possíveis soluções; como material de apoio e de consulta durantes as atividades, cartazes com informações sobre doenças de veiculação hídrica, soluções descentralizadas de esgotos e formas seguras de abastecimento e tratamento domiciliar de água, além da "árvore”, eram mantidos expostos em varais (Figura 4a,b).

Figura 4. Oficinas participativas sobre segurança da a água para consumo humano 


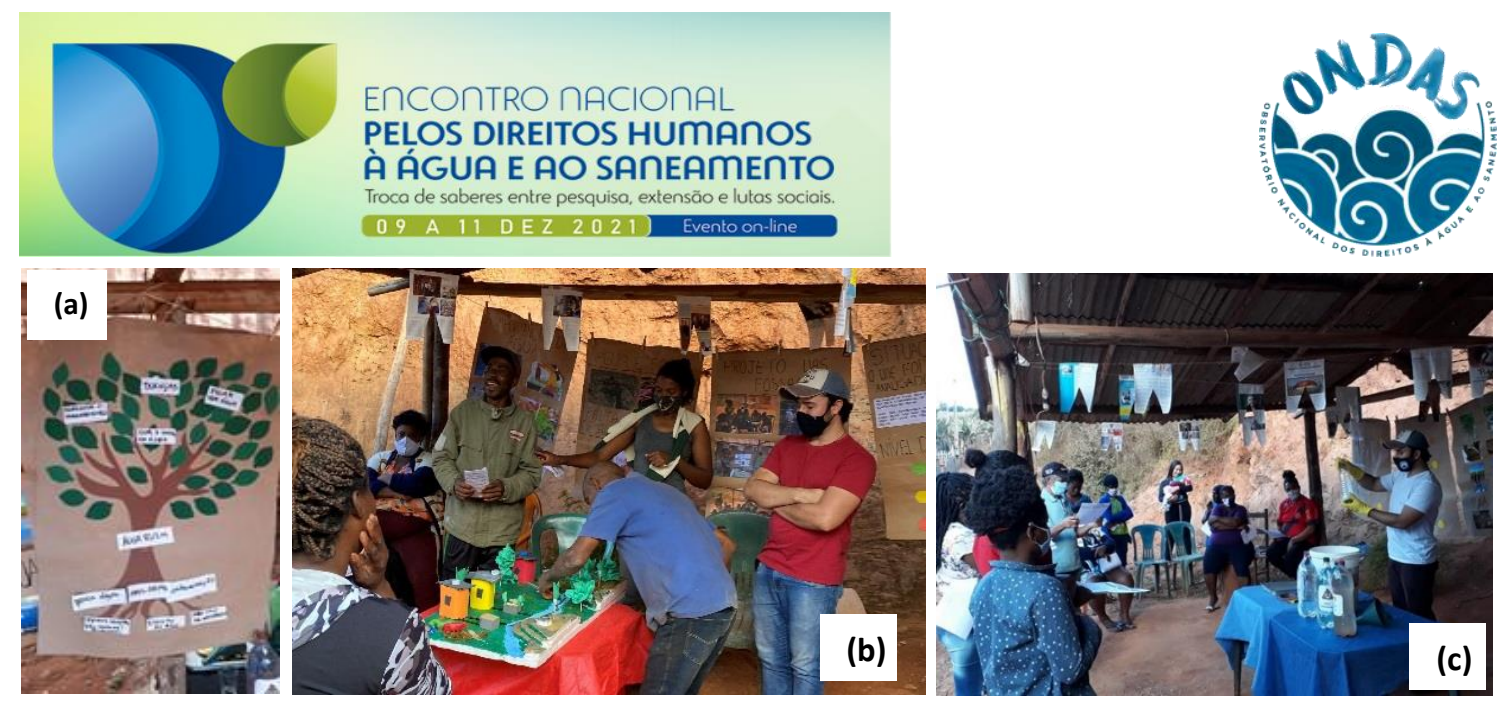

\section{Seleção de tecnologias e das residências a serem atendidas: oficinas expositivas dialogadas}

À exemplo da Fase 1, a escolha das soluções foi precedida por uma oficina expositiva /demonstrativa, dialogada, em que foram discutidos métodos e técnicas de abastecimento e tratamento domiciliar de água (Figura 4c), incluindo aspectos de: operação e manutenção, custos, eficiência de tratamento, sustentabilidade. Como material de apoio, foram preparados cartazes (afixados no local) e cartilhas e folders (distribuídos às pessoas), com informações sobre qualidade da água, orientações para cloração domiciliar da água, manutenção de filtros de cerâmica e limpeza de caixas d'água. Um desses folders trazia um esquema de perguntas na forma de fluxograma, de forma a avaliar a situação de segurança / risco de fontes de água (poços e nascentes). Após discussão de prós e contras, as opções foram ordenadas por prioridade. A seguir, por votação, com base em procedimentos e critérios semelhantes aos adotados na Fase 1, por votação, foram definidas as residências a serem atendidas

\section{CONCLUSÕES}

Entende-se (com base, inclusive, em depoimentos de pessoas da comunidade colhidos em pesquisa qualitativa) que os recursos metodológicos utilizados contribuíram para que se concretizassem as propostas pedagógicas do projeto: criação de ambiente favorável à contextualização, problematização, elucidação de conflitos, construção de consensos e construção compartilhada de conhecimentos, mediante a mobilização e participação e a relação dialógica entre saberes técnico e popular (senso comum). Propiciaram, assim, o alcance dos objetivos maiores do projeto: além da implantação de melhorias de saneamento que se mostrem sustentáveis, a tomada de consciência e empoderamento da comunidade no entendimento do, e na busca pelo, saneamento como direito humano.

\section{AGRADECIMENTOS}

À Secretaria de Desenvolvimento Agrário do Estado de Minas Gerais e ao Ministério Público do Trabalho de Minas Gerais pelo financiamento do projeto de extensão.

\section{REFERÊNCIAS}

ALBUQUERQUE, C. Manual prático para a realização dos direitos humanos à água e ao saneamento pela relatora especial da ONU, Catarina de Albuquerque. Cap. 4: Princípios. Portugal: OHCHR, 2014.

CHAMBERS, R.. The origins and practice of participatory rural appraisal. World development, v. 22, n. 7, p. 953-969, 1994.

CAPOBIANGO, G. V. Reflexões sobre o processo de seleção de soluções de saneamento em uma comunidade quilombola na Zona da Mata - MG: Participação e percepção da comunidade, diálogos entre os saberes técnico e popular. Dissertação (Mestrado em Engenharia Civil), 2019, 152f. Departamento de Engenharia Civil, Universidade Federal de Viçosa, Viçosa, 2019.

CATAlÃO, V. M. L. e RODRIGUES, M. S. (Orgs). Água como matriz ecopedagógica: um projeto a muitas mãos. Brasília: Departamento de Ecologia da Universidade de Brasília, p.82-94, 2006. 
FREIRE, Paulo. Pedagogia da autonomia: saberes necessários à prática educativa. 24. ed. São Paulo: Paz e Terra, 1996.

OLIVEIRA, M.L.R. Reflexões sobre o uso de metodologias participativas como instrumento de trabalho em comunidades rurais. Em Extensão, v. 14, n. 1, p. 30-51, 2015.

PEREIRA, J. R. Diagnóstico rápido participativo emancipador: a base para o desenvolvimento sustentável dos assentamentos da reforma agrária. Viçosa-MG: Editora da UFV, 1998

SANTOS, T. C. C. Implantação de sistemas individuais de esgotos em uma comunidade quilombola na Zona da Mata MG: estudos de concepção e aspectos construtivos. Monografia (Graduação em Engenharia Civil), 2018, 75f. Departamento de Engenharia Civil, Universidade Federal de Viçosa, Viçosa, 2018.

SCHÜTZ, G. E.; HACON, S.; IGNOTTI, E.. GEO Health: Methodology for integrated environment and health assessment - A focus on Latin America and the Caribbean. World Health Organization, Pan American Health Organization, United Nations Environment Programme. Ciudad del Saber: UNEP; 2009.

SOUZA, M. M. O. A utilização de metodologias de diagnóstico e planejamento participativo em assentamentos rurais: o diagnóstico rural/ rápido participativo (DRP). Em extensão, v. 8, n. 1, p. 34 - 47, 2009.

SOUZA, C. M.; COSTA, A. M.; MORAES, L. R. S.; FREITAS, C. M. de. Saneamento: promoção da saúde, qualidade de vida e sustentabilidade ambiental. Scielo-Editora FIOCRUZ, 2015. 140p.

VERDEJO, M. E.. Ministério do Desenvolvimento Agrário. Secretaria da Agricultura Familiar. Diagnóstico Rural Participativo: Guia Prático DRP. Brasília: Secretaria de Agricultura Familiar, 2006. 